:. I will certainly do all I can to promote any such idea.'

Mr. Robert Newstead (Chester) writes :-_ You would have my heartiest support in the matter, as I feel that such an institution would be of material benefit to the Agriculturists and Horticulturists of this country."

Mr. A. E. Shipley (Cambridge) writes:-"I should welcome the founding of an Association of Economic Biologists if you think we are really strong enough. . . If the Association is formed I hope it will be a really working one."

Mr. Cecil Warburton (Cambridge) writes :- “I heartily approve of your suggestion with regard to the formation of an Association of Economic Biologists in this country."

Similar letters or expressions of opinion have been received from Dr. A. H. R. Buller, Mr..Herbert Stone, and others.

The University, Birmingham, May 30.

\title{
THE RELATION OF HUMAN TO BOVINE
} TUBERCULOSIS.

THE Royal Commission appointed to inquire into the relation of human and animal tuberculosis has presented an interim report published on June $\mathrm{I}$. The Commission was appointed in August, I9oI, soon after Prof. Koch's address had been delivered at the British Congress on Tuberculosis held in London in July, Igor, in which he stated that as the result of experiments on animals, cattle, pigs, asses, sheep, and goats, he "felt justified in maintaining that human tuberculosis differs from bovine tuberculosis, and cannot be transmitted to cattle," and he also stated that "though the important question whether man is susceptible to bovine tuberculosis at all is not yet absolutely decided, and will not admit of absolute decision to-day or to-morrow, one is, nevertheless, at liberty to say that, if such a susceptibility really exists, the infection of human beings is but of very rare occurrence. I should estimate the extent of the infection by the milk and flesh of tuberculous cattle and the butter made of their milk as hardly greater than that of hereditary transmission, and I, therefore, do not deem it advisable to take any measures against it." According to Koch the chief danger of infection is from human tuberculous sputum. He suggested as the most important means of combating the disease the improvement of general hygienic conditions, provision of suitable hospitals and sanatoria for consumptives, and inspection and disinfection.

Lord Lister, at the conclusion of Prof. Koch's address, struck a note of warning. He pointed out " how serious and grievous a thing it would be if the rules now in force for securing purity of milk supply should be relaxed; and it should turn out after all that the conclusion was erroneous." This attitude was taken up by a number of other leading pathologists. Since Koch's statement a number of workers have published the results of experiments on the subject, and the bulk of the evidence has been opposed to Koch's view.

The most striking and interesting pronouncement on the subject has been from one of Koch's most distinguished pupils, von Behring, who on this subject places himself in a position entirely opposed to that of his old master. To many minds von Behring's view appears to be as extreme as Koch's. He holds that "the main source to which phthisis must be traced is the mill diet of infants." $\mathrm{He}$ found that in young animals such as guinea pigs, owing to the incomplete continuity of the epithelium, numerous bacilli, and among them the tubercle bacillus, could pass through the wall of the alimentary canal, giving rise to a tuberculosis of the cervical glands of the type

Nu. 1806, voL. 7o]

of scrofula in the human subject, and that at a later period these animals not infrequently developed a type of tuberculosis which has been regarded as indicative of inhalation tuberculosis. The freedom with which milk-bacilli find their way through the walls of the alimentary tract into the circulation owing to the incomplete continuity of the epithelium and absence of active ferment secretion in young animals makes " the disposition to tuberculous infection entirely physiological and normal." At a later period in life a similar susceptible state may be induced by the exanthemata such as scarlet fever and measles. Von Behring, along with Römer, has also shown that immunity may be conferred on bovines by injection of tubercle bacilli of human origin, a striking argument in favour of the specific relationship of the two types of bacilli. These views, which have appeared since the appointment of the Commission, have only emphasised the need of further investigation.

The commissioners state that they felt it their duty to publish this interim report because the experimental results obtained by them are so striking.

The Commission was to inquire and report with respect to tuberculosis:-

(I) Whether the disease in animals and man is one and the same.

(2) Whether animals and man can be reciprocally infected with it.

(3) Under what conditions, if at all, the transmission of the disease from animals to man takes place, and what are the circumstances, favourable or unfavourable, to such transmission.

The first line of inquiry upon which the Commission entered was to ascertain the effects produced by introducing into the body of the bovine animal, either through the alimentary canal as food or directly into the tissues by subcutaneous or other injection, tuberculous material of human origin, that is, material containing living tubercle bacilli obtained from various cases of tuberculous disease in human beings, and how far these effects resembled or differed from the effects produced by introducing into the bovine animal under conditions as similar as possible tuberculous material of bovine origin, that is, material containing living tubercle bacilli obtained from cases of tuberculous disease in the cow, calf, or ox. More than twenty strains of tubercle bacilli have been employed, that is to say, the material taken from more than twenty cases of tuberculous disease in human beings. The effects produced were compared with those resulting from the injection of different strains of tuberculous material of bovine origin. In the case of seven of the above strains of human origin the injection of the human tuberculous material into cattle gave rise at once to acute tuberculosis, with the development of widespread disease in various organs of the body. In some instances the disease was of remarkable severity. In the case of the remaining strains the effects were less marked. The tuberculous disease was either limited to the spot where the material was introduced (this occurred, however, in two instances only, and these at the very beginning of their inquiry), or spread to a variable extent from the site of inoculation along the lymphatic glands with, at most, the appearance of a very small amount of tubercle in such organs as the lungs and spleen. Material, however, taken from the bovine animal thus affected and introduced into other bovine animals has, up to the present, in the case of at least five of these remaining strains, ultimately given rise in the bovine animal to general tuberculosis of an intense-character. The disease thus set up in the bovine animal by material of human origin has been compared with that set up 
in the bovine animal by material of bovine origin, and so far, both in broad, general features, and finer histological details, the two conditions have been found to be identical. The commission has, so far, failed to discover any character by which the one could be distinguished from the other, and the records contain accounts of the post mortem examination of bovine animals infected with tuberculous material of human origin, which might be used as typical descriptions of ordinary bovine tuberculosis.

There is no doubt that this interim report will be useful in strengthening the hands of local authorities, medical officers of health, and others, who have been struggling in difficult circumstances to obtain for the people a purer milk supply and food free from tuberculous contamination. As stated by the commissioners, the results obtained seem " to show quite clearly that it would be most unwise to frame or modify legislative measures in accordance with the view that human and bovine tubercle bacilli are specifically different from each other, and that the disease caused by the one is a wholly different thing from the disease caused by the other."

G. D.

\section{THE INTERNATIONAL ASSOCIATION OF ACADEMIES.}

A COPY of the official record of the proceedings of the International Association of Academies at its plenary meeting on May 25, and of the proceedings of the section of science on the following day, has now been received from the Royal Society. The complete protocol of the meeting cannot yet be made up, because no report has yet been received of the proceedings of the section of letters; but we are informed that the proceedings on the last day of the general assembly in their plenary meeting consisted mainly of receiving the resolutions of the sections of science and of letters, and of certain complimentary resolutions with regard to the president of the meeting and to the Royal Society.

In the subjoined summary the foreign translations of the resolutions and details of the discussions have been omitted.

Wednesday, May 25.--After a few words of welcome from the president of the council (Sir M. Foster), Prof. Darboux (Secrétaire perpétuel de 1'Académie des Sciences) proposed Sir Michael Foster as president of the general assembly. The proposal was carried by acclamation.

The president opened the proceedings with an address, in the course of which he said:- -

I accept with pleasure, though not without anxiety, the duties of the honourable though arduous post in which you have placed me, and trust that such short-comings as I may disclose may prove as little hindrance as possible to the success of our meeting. When we met in Paris our association was an infant of some fifteen months; it had just begun its dentition. It is now a lusty child of four years and more; it has cut all of its first set of teeth. I feel sure that you will join with me in the hope that its teeth will be used, never for secondary purposes, as aggressive weapons, but always for primary purposes, for carrying out the first stages of the digestion and assimilation of scientific knowledge and scientific thought into living active scientific flesh and blood. When I say "scientific" I use the word in the broad sense used by my illustrious predecessor in this chair, in his opening address at Paris, as meaning all knowledge which is exact and which can be verified. Though we call the two sections into which we divide ourselves, the one "scientific," the other "literary," we are none of us, I venture to say, satisfied with our nomenclature. We wish, all of us, that we could use names which should free us from the mere suspicion that there is even the taint of antagonism between the kinds of knowledge with which we have to deal.
The association began as a brotherhood of existing academies, but it has already advanced from brotherhood to parentage. At a meeting at Paris, the Royal Society of Lendon excited much sympathy by its lone condition; while the delegates of most other countries represented the whole round of knowledge with which the association deals, those of England could speak of one part only. That sympathy provoked action, and led to the establishment of the British Academy for the Promotion of Historical, Philosophical and Philological Studies; and it has been one of the pleasant duties of my three years' term of office to bring about the admission of that academy into our fold.

One of the matters brought before the council of the association last year, concerning the relations of the association to proposals for international investigations requiring State aid, is placed on the agenda for the present meeting. The subject is one which demands our most anxious attention; may we be able to come to a decision which, while assuring the future usefulness of the association, may not tend to hamper scientific activity outside ourselves. On another matter, namely, the question whether the association should hold property, the council came to the conclusion that it was undesirable to attempt at present a definitive decision; and there the matter at present stands. The question does not come up for consideration at the present meeting, but it is one on which a decision must, sooner or later, be taken.

On the motion of Prof. Diels, Lord Reay was nominated vice-president.

Secretaries for the meeting were nominated as follows :German, Dr. K. Krumbacher, Munich; French, M. A de Lapparent, Paris; English, Dr. A. D. Waller, London.

The president proposed the following delegates as Présidents d'honneur:-Dr. Diels, Prof. Darboux, Count Balzani, Dr. Bakhuyzen.

Prof. Gomperz proposed that section ix. (4), (5), of the statutes be amended to read as follows:-Section ix. (4). The president (of the council) shall be appointed by the directing academy. Section ix. (5). The vice-president, who shall belong to the other section, shall be appointed in the same way. In the event, however, of the directing academy having only one section, the association shall entrust the appointment of the vice-president to another academy. The proposal was carried.

Prof. Darboux moved "That the initiation of any new international organisation, to be maintained by subventions from different States, demands careful previous examination into the value and objects of such organisation, and that it is desirable that proposals to establish such organisations should be considered by the International Association of Academies before definite action is taken." The resolution was carried.

Prof. Armstrong presented the draft report of the executive committee of the International Catalogue of Scientific Literature. Prof. Credner moved "That this meeting recognises the great value of the International Catalogue of Scientific Literature, and the importance of aiding the work by making its existence known, as well as of contributing to its efficiency and completeness by endeavouring to secure the indexing of scientific publications at the time of issue, in accordance with the plan adopted by the Royal Society." "The resolution was carried unanimously.

Mr. Bryce announced that the British Academy was taking steps to publish a similar catalogue for philology, and the other branches of learning not included among the sciences of nature.

M. Boutroux gave a brief account of the work completed and contemplated in connection with the preparation of a complete edition of the works of Leibniz, and moved "That the association be requested to renew the commission to the three academies above named to prepare an edition of the works of Leibniz committed to them by the resolution of the association of April I8, I901, and to request them to bring about, between now and the general assembly of the association in 1907 , the publication of a critical catalogue, for which they have already collected the materials, of the Leibniz manuscripts." The resolution was carried.

The president proposed Vienna as the place of meeting of the next general assembly in 1907. The proposal was adopted unanimously. 